\title{
PEMBUATAN BAHAN BAKAR CAMPURAN BIODIESEL, DIESEL, ETANOL DAN AIR DALAM EMULSI STABIL
}

\author{
Meiga Paendong'), Hanny F. Sangian ${ }^{1)}$, Maria D. Bobanto ${ }^{1)}$ \\ ${ }^{1}$ Program Studi Fisika FMIPA UNSRAT Manado, 95115
}

\begin{abstract}
The purpose of this research is to prepare a blended fuel of biodiesel, diesel and ethanol in stable emulsion. Biodiesel which is mixed with diesel and ethanol in certain compositions was conducted manually. The first step was to prepare ethanol from fermented palm sap and then the ethanol and water were distililed using a reflux separator. The ethanol obtained was with purity 94-96\%, while 97\% ethanol was produced by lime absorbsion. The next step was the mixing process between ethanol, biodiesel and ethanol, biodiesel, and diesel. Ethanol was poured into a measuring flask with a volume of $7 \mathrm{ml}$ and then biodiesel was added until they formed a stable emulsion solution. The ethanol and diesel were mixed and the biodiesel was added gradually while shaken slowly forming a stable emulsion. The results showed that the composition of biodiesel, ethanol, and water with $96 \%$ ethanol were 78.76, 20.42 and $0.81 \%(\mathrm{v} / \mathrm{v})$, where methyl esters were obtained from palm oil using subcritical techniques. Meanwhile, biodiesel from coconut oil with the same technique, the composition of the three components was $75.13 \%$ biodiesel, $23.90 \%$ ethanol and $0.95 \%$ air.
\end{abstract}

Keywords: Biodiesel, Ethanol, Diesel, Palm Tree (Arenga pinnata SP).

\begin{abstract}
ABSTRAK
Tujuan penelitian ini adalah membuat bahan bakar campuran larutan emulsi stabil dengan mencampurkan biodiesel, diesel dan etanol. Biodiesel yang dicampur dengan diesel dan etanol pada komposisi tertentu dilakukan secara manual. Tahapan yang pertama yaitu pembuatan etanol dari nira aren yang sudah terfermentasi dan kemudian dilakukan proses destilasi etanol untuk mendapat kemurnian 94-96\%, sementara untuk etanol $97 \%$ didapat dengan cara absorsi menggunakan lime. Tahapan berikutnya yaitu proses pencampuran dilakukan dengan menggunakan etanol dengan kemurnian 94\%-97\%. Etanol dituangkan ke dalam gelas ukur dengan volume $7 \mathrm{ml}$ dan etanol konsentrasi $96 \%$ dicampur secara perlahan hingga membentuk larutan emulsi stabil. Hasil menunjukan bahwa komposisi biodiesel, etanol, dan air dengan kosentrasi etanol 96\% adalah 78.76, 20.42 dan $0.81 \%$ (v/v) yang mana methyl ester diturunkan dari minyak sawit dengan menggunakan teknik subkritis. Sementara, biodiesel dari minyak kelapa dengan teknik yang sama, komposisi ketiga komponen adalah $75.13 \%$ biodiesel, $23.90 \%$ etanol dan $0.95 \%$ air.
\end{abstract}

Kata kunci: Biodiesel, Etanol, Diesel, Pohon Aren (Arenga pinnata SP) 


\section{PENDAHULUAN}

Saat ini para ahli berusaha untuk mmengembangkan sumber bahan terbarukan lingnoselulosa dan pati untuk di ubah menjadi bahan yang lebih berharga dengan cara preatreatment (Sangian et al. 2018 ${ }^{\mathrm{a}}$ ); (Sangian et al. 2018 ${ }^{\mathrm{b}}$ ); (Sangian et al. $2018^{\mathrm{c}}$ ).

Krisis bahan bakar fosil dan emisi gas buang dewasa ini menjadi permasalahan yang kompleks dengan meningkatnya jumlah kendaraan baik di negara maju dan berkembang. Produksi bahan bakar minyak bumi (fosil) yang tidak dapat mengimbangi besarnya konsumsi bahan bakar minyak menjadi permasalahan utama di Indonesia karena cadangan dan produksi minyak bumi mengalami penurunan sebesar $10 \%$ per tahun (Bambang, 2006).

Etanol merupakan sumber energi yang dapat diperbarui. Sebagai salah satu bahan bakar, etanol yang dihasilkan dari fermentasi glukosa yang bisa didapatkan dari tanamantanaman yang banyak mengandung karbohidrat (Govindaswamy \& Vane, 2007)

Di Sulawesi Utara, etanol didapat dari pohon aren (Arenga prinnata) yang merupakan pohon palem lokal dan nira yang dihasilkan disebut dengan saguer. Hasil studi menunjukkan bahwa seratus liter nira dimasukkan di dalam plastik untuk difermentasi selama 4-5 hari. Dengan menerapkan destilasi reflux, maka etanol yang dihasilkan bisa mencapai kemurnian 96\% tergantung pada suhu kolom (Sangian et al., 2017).
Bahan bakar solar (minyak diesel) merupakan salah satu jenis bahan bakar yang dihasilkan dari proses pengolahan minyak bumi mentah, dan pada dasarnya minyak mentah dipisahkan fraksi-fraksinya pada proses destilasi sehingga titik didih solar $250^{\circ} \mathrm{C}$ sampai $300^{\circ} \mathrm{C}$ (Chen et al., 2007).

Biodiesel berasal dari bahan baku terbarukan dan sebagai ester monoalkil dari asam lemak rantai panjang. Biodiesel sendiri telah diteliti dan sebagai kemungkinan pengganti bahan bakar konvensional sejenis yang diperoleh dari trigliserida oleh transesterifikasi masing-masing dengan metanol/etanol. Pembuatan untuk bahan biodiesel ini terbuat dari minyak bunga matahari, minyak goreng bekas, minyak kelapa, minyak sawit yang merupakan sumber trigliserida (Sum \& Sandler, 2000).

Menurut (Shi et al., 2006) bahwa penggunaan bahan bakar campuran alkoholbiodiesel-solar dengan rasio: $5 \%: 20 \%: 75 \%$ dapat mengakibatkan penurunan emisi partikulat (PM) yang cukup signifikan namun terjadi peningkatan pada emisi NOx sebesar 2-14\%. Sedangkan berdasarkan hasil penelitian yang telah dilakukan oleh (Yilmaz, 2012) bahwa pencampuran bahan bakar biodiesel-alkohol-solar pada penggunaan mesin bakar, terjadi penurunan emisi $\mathrm{CO}$ dan HC namun konsumsi bahan bakar dalam pembakaran menjadi meningkat dibandingkan dengan solar murni. 
Bahan bakar campuran etanol, biodiesel dan air sangat penting untuk dilakukan karena dapat mengganti penggunaan sebagian bahan bakar fosil. Penelitian ini diarahkan untuk membuat bahan bakar dengan beberapa perbandingan antara diesel, etanol dan biodiesel untuk dibuat menjadi larutan emulsi stabil. Biaya pembuatan bahan bakar campuran ini lebih rendah dari yang dibuat sebelumnya karena menggunakan etanol dengan kemurnian di bawah $97 \%$. Konsentrasi etanol yang akan dicampur dengan biodiesel untuk didapatkan emulsi stabil divariasikan mulai dari $93 \%$ sampai 97 $\%$ dan pencampuran diesel, etanol dan biodiesel dilakukan secara manual dengan cara dilarutkan.

\section{METODOLOGI PENELITIAN}

Alat

Alat yang digunakan: Gelas ukur, kondesor, boiler, thermometer.

\section{Bahan}

Etanol, Diesel, Biodiesel (minyak kelapa), dan (minyak sawit).

\section{Prosedur Kerja}

\section{Prosedur Pembuatan Etanol 96\%}

Hasil fermentasi dari nira aren kemudian dituangkan kedalam boiler dan dipanaskan untuk memisakan air dari bioetanol. Suhu dalam boiler dikontrol dengan termometer dan suplai gas pada kompor. Uap yang diproduksi akan naik kedalam kolom kemudian mengembun pada packing material dan menetes kebawah (refluks), dengan suhu antara 70 dan $78^{\circ} \mathrm{C}$ yang merupakan perkiraan titik didih etanol. Proses ini akan berlangsung secara terus-menerus hingga pada kolom berikutnya sampai bioetanol mencapai kemurnian yaitu mendekati $95 \%$ sampai 96 $\%$. Dalam proses pemisahan ini perlu dilakukan pengontrolan jumlah refluks uap pada kolom. Pada bagian atas kolom dihubungkan ke kondensor untuk mendinginkan uap kembali ke bentuk cair. Kondensor ini dibangun pipa koaksial, pipa saluran dan pipa luar yang mana terdiri dari saluran air dingin dan air panas dalam kondenser. Cairan yang telah didinginkan pada kondenser merupakan hasil akhir dari proses destilasi bioetanol dan ditampung ke dalam gelas ukur.

\section{HASIL DAN PEMBAHASAN}

\section{Pemisahan antara Etanol Dengan Air}

Penelitian dimulai pukul 09.30 wita yaitu pada proses pemanasan kaldu dengan suhu awal yang terbaca oleh sensor adalah $35^{\circ} \mathrm{C}$. Setelah selang waktu 125 menit sejak awal proses separasi, suhu naik menjadi 78.3 ${ }^{\circ} \mathrm{C}$ dan etanol mulai menetes dari ujung kondensor. Selanjutnya untuk konsentrasi 63 $\%$ suhunya berubah menjadi $83^{\circ} \mathrm{C}$ dan volume etanol dalam erlen meyer menjadi $100 \mathrm{ml}$, dan diukur tingkat kemurniannya dengan menggunakan alat uji konsentrasi dan untuk konsentrasi awal didapat $83 \%$. Kemudian didapatkan konsentrasi etanol $94 \%$ dimana suhunya semakin menurun menjadi $78{ }^{\circ} \mathrm{C}$ dan 
$96 \%$ dengan suhu $78,5^{\circ} \mathrm{C}$ yang menjadi konsentrasi akhir Penelitian.

\section{Proses pencampuran biodiesel, etanol dan} diesel dengan konsetrasi etanol 94-97\%.

Adapun alat dan bahan berupa gelas ukur, alat ukur konsentrasi etanol, biodiesel dan diesel.

Ditentukan konsentrasi etanol yaitu $94 \%$ sampai $97 \%$ dan ditentukan dengan menggunakan alat ukur alkohol meter. Jumlah volume etanol ditentukan yaitu $7 \mathrm{ml}$ dengan konsentrasi etanol yang berbeda dan biodiesel ditambahkan secara perlahan-lahan sampai membentuk larutan emulsi stabil. Biodiesel, diesel dan etanol dimasukkan ke dalam gelas ukur dengan volume etanol $7 \mathrm{ml}$ untuk dibuat menjadi larutan emulsi stabil. Dalam pencampuran ini dilakukan dengan beberapa perbandingan, Etanol 94\% ditambahkan kedalam gelas ukur dengan volume diesel 7$20 \mathrm{ml}$. Kemudian untuk larutan biodiesel di tambahkan secara perlahan-lahan sampai larutan sudah tidak terpisah lagi. Dengan proses yang sama (untuk kemurnian etanol 95 $\%$ sampai $97 \%$ dicampurkan dengan diesel dan biodiesel

Proses Pencampuran Biodiesel (POME), Diesel, Etanol dan Air Teknik Transesterifikasi Konvensional

Penelitian dimulai dengan mempersiapkan alat dan bahan yang digunakan seperti gelas ukur, alat uji konsentrasi, biodiesel dan etanol. Adapun kemurnian etanol yang digunakan dalam proses pencampuran yaitu $94 \%, 95 \%, 96 \%$, dan $97 \%$ dengan beberapa perbandingan yang diambil. Dalam pencampuran ini biodiesel yang digunakan ada 2 jenis yaitu teknik trans-esterifikasi konvensional dan biodiesel teknik subkritis.

Keterangan : POME (Palm Oil Metil Ester)

COME (Coconut Oil Metil

Ester)

Proses pencampuran diawali dengan pencampuran biodiesel (POME), etanol dan air untuk konsentrasi etanol mulai dari $97 \%$ sampai $94 \%$ dalam pencampuran yang pertama dimana biodiesel yang digunakan adalah minyak sawit dengan teknik transesterifikasi konvensional. Etanol (hidrat) berkonsentrasi $97 \%$ ditambahkan ke dalam gelas ukur secara perlahan dengan volume 7 $\mathrm{ml}$ dan untuk volume biodiesel yang ditambahkan $2 \mathrm{ml}$ sehingga larutan sudah tidak terpisah lagi hal ini disebabkan karena konsentrasi etanol yang tinggi. Pada pencampuran etanol $94 \%$ untuk volume awal yang ditambahkan $15 \mathrm{ml}$ terlihat bahwa biodiesel masih menggambang diatas permukaan larutan etanol hal ini disebabkan oleh massa jenis etanol dan jika dilakukan penambahan biodiesel sebanyak $23 \mathrm{ml}$ sudah terlihat bahwa larutan menjadi emulsi stabil.

\section{Komposisi Biodiesel (POME), Diesel, Etanol dan Air Menggunakan Teknik Subkiritis}


Untuk pencampuran ini berbeda dengan yang sebelumnya karena biodiesel yang di gunakan teknik subkritis dengan memiliki $\mathrm{T}=17$ Bar, konsentrasi etanol dalam pencampuran ini yaitu $97 \%$ sampai $94 \%$ dengan volume etanol yang konstan $7 \mathrm{ml}$. Pada proses pencampuran menggunakan teknik subkritis. Pada komposisi biodiesel (POME), etanol (95\%) dan diesel dalam emulsi stabil, untuk jumlah volume diesel divariasikan dengan konsentrasi etanol $95 \%$ dalam penambahan biodiesel sebanyak $44 \mathrm{ml}$ dan $10 \mathrm{ml}$ diesel, untuk pencampuran ini memerlukan penambahan biodiesel yang banyak. Untuk konsentrasi etanol di bawah 95 $\%$ dalam larutan yang dicampurkan terlihat butiran-butiran (droplets).

Komposisi Biodiesel, Diesel, Etanol, dan Air Menggunakan Teknik Transesterifikasi konvensional

Pada proses pencampuran dilakukan sama hal nya dengan sebelumnya namun biodiesel yang dipakai menggunakan minyak kelapa. Untuk konsentrasi etanol yang digunakan yaitu $97 \quad \%$ sampai dengan $94 \quad \%$ dan dilakukan dengan beberapa perbandingan. Pencampuran yang pertama untuk konsentrasi etanol konstan atau tetap $7 \mathrm{ml}$. Proses yang dilakukan adalah mencampurkan etanol dan biodiesel dengan menggunakan konsentrasi etanol $97 \%$ untuk biodiesel ditambahkan secara perlahan-lahan hingga $18 \mathrm{ml}$, jika dicampurkan larutan sudah tidak terpisah dan menjadi larutan emulsi stabil adapun selisi air yang dihitung dalam larutan ini yaitu 0,21. Dapat dilihat dalam perhitungan persentase semakin banyak jumlah volume biodiesel maka volume etanol semakin berkurang yang artinya biodiesel terlarut sepenuhnya.

\section{Analisis Tengangan Permukaan}

Hal lain yang mempengaruhi proses pencampuran biodiesel, diesel dan etanol hingga menjadi emulsi stabil adalah interaksi yang dimiliki gugus atom pada molekul masing-masing larutan dimana etanol dan air (polar) akan saling menyatu melalui ikatan hidrogen, sedangkan etanol dan diesel (nonpolar) dapat menjadi emulsi stabil oleh karena adanya muatan parsial yang dimiliki oleh atom hidrogen sehingga pada keadaan tertentu atom tersebut saling tarik-menarik maupun tolak-menolak terhadap atom hidrogen yang lain. Untuk pencampuran biodiesel dan etanol dapat bersatu pada konsentrasi tertentu karena biodiesel sebagai surfaktan yang menghubungkan antara polar dan non polar (Sum dan Sandler, 2000).

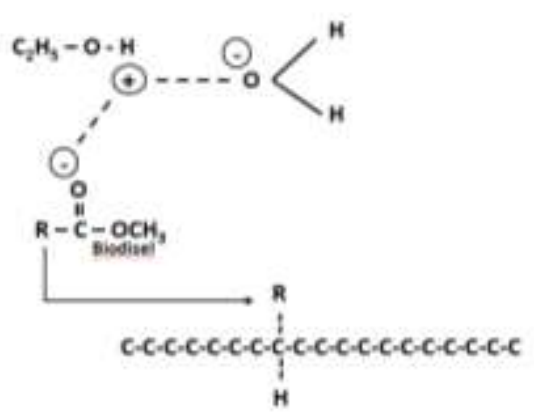

Gambar 1. Struktur Etanol, Biodiesel dan Diesel 


\section{Analisis Triangular}

Berdasarkan data campuran bahan bakar larutan emulsi stabil dengan komposisi biodiesel, diesel dan etanol menunjukkan bahwa peningkatan jumlah biodiesel mempengaruhi komposisi diesel dan etanol dalam emulsi stabil. Pada gambar 3. Bagian yang diarsir warna biru merupakan emulsi stabil dan yang tidak diarsir merupakan larutan tidak stabil (dua fasa).

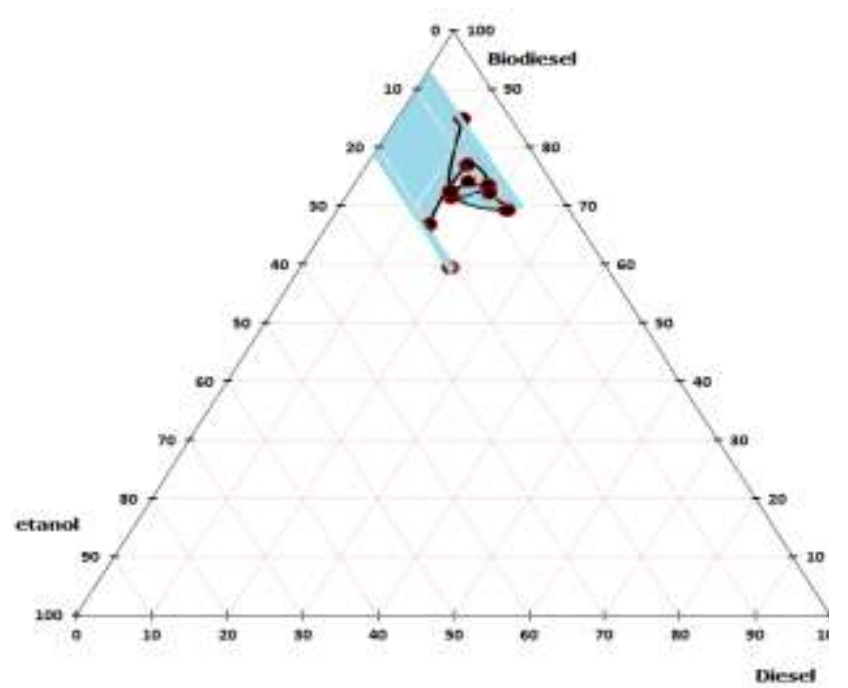

Gambar 2. Triangular Hubungan antara biodiesel POME (cara biasa ), diesel dan etanol

\section{KESIMPULAN}

1. Pencampuran etanol $97 \%$ dengan biodiesel, diesel dan air hanya membutuhkan volume etanol yang sedikit. Sedangkan untuk pencampurkan etanol $94 \%$ dengan biodiesel, diesel dan air membutuhkan volume etanol yang banyak.
2. Dalam pembentukan larutan emulsi stabil antara biodiesel, diesel dan etanol berfungsi sebagai surfaktan yang mempunyai kutub polar dan nonpolar.

\section{SARAN}

Perlu dikembangkan dalam uji coba mesin yang termodifikasi

\section{DAFTAR PUSTAKA}

Aruan, I., Sangian, H. F., \& Tanauma, A. (2018). Efek Perubahan Struktur Pati Singkong Yang Dilakukan Pretreatment Dengan Larutan Ion Dan Gelombang Mikro Terhadap Produksi Gula. Jurnal MIPA, 7(1), 34.

Bambang. 2006. Biodiesel Sumber Energi Alternatif Pengganti Solar Yang Terbuat Dari Ekstraksi Minyak Jarak Pagar. Surabaya: Trubus Agrisarana.

Govindaswamy, S., \& Vane, L. M. (2007). Kinetics of growth and ethanol production on different carbon substrates using genetically engineered xylose-fermenting yeast. 98, 677-685.

Hansen, A. C., Zhang, Q., \& Lyne, P. W. L. (2010). Ethanol - diesel fuel blends - a review. 96(2005), 277-285.

Sangian, H. F., Tunena, M., \& Pani, S. (2017). The study of isochoric subcritical water using power series: A potential of energy generation with ISCW reactor. AIP Conference Proceedings, 1887(September).

Sehe, M. Ri., Sangian, H. F., \& Tongkukut, S. H. . (2018). Studi Perbandingan Struktur Selulosa Dengan Pretreatment Larutan Ion Pada Kayu Cempaka (Elmerillia Ovalis). Jurnal MIPA, 7(1), 1. 
Shi, X., Pang, X., Mu, Y., He, H., \& Shuai, S. (2006). Emission reduction potential of using ethanol - biodiesel - diesel fuel blend on a heavy-duty diesel engine. 40, 2567-2574.

Sum, A. K., \& Sandler, S. I. (2000). Ab initio calculations of cooperativity effects on clusters of methanol, ethanol, 1propanol, and methanethiol. Journal of Physical Chemistry A, 104(6), 11211129.

Yilmaz, N. (2012). Comparative analysis of biodiesel-ethanol-diesel and biodieselmethanol-diesel blends in a diesel engine. Energy, 40(1), 210-213. 